JGG 2021;69:241-246

doi: $10.36150 / 2499-6564-N 449$

Clinical Geriatrics - Reviews

\title{
Sarcopenia, malnutrition, and frailty: disease implications for geriatric DM patients
}

\author{
Massimiliano Petrelli \\ Clinic of Endocrinology and Metabolic Diseases, University Hospital "Ospedali Riuniti", Ancona, \\ Italy; Italian Society of Diabetology, Rome, Italy
}

\section{RECOMMENDATIONS}

A. Due to the risk of sarcopenia, the treatment of DM in geriatric patients should be individualized according to the patient's characteristics, associated comorbidities, and DM complications, which may increase the risk of sarcopenia. It is preferable, where possible, to work within a multidisciplinary team including general practitioner diabetologist, geriatrician, dietologist and dietician, physiatrist and physiotherapist.

B. Geriatric DM patients should be categorized as:

1 Patients with DM and obesity;

2 Patients with DM and malnutrition;

3 Patients with DM and comorbid diseases or diabetes complications that may increase the risk of sarcopenia.

C. Recommendations for all three types of patients are to:

Received: July 30, 2021

Accepted: September 16, 2021

\section{Correspondence}

Massimiliano Petrelli

Clinic of Endocrinology and Metabolic Diseases, University Hospital "Ospedali Riuniti", via Conca 71, 60126 Torrette - Ancona, Italy

E-mail: Massimiliano.Petrelli@ospedaliriuniti. marche.it

How to cite this article: Petrelli $M$. Sarcopenia, malnutrition, and frailty: disease implications for geriatric DM patients. Journal of Gerontology and Geriatrics 2021;69:241-246. https://doi. org/10.36150/2499-6564-N449

(C) Copyright by Società Italiana

di Gerontologia e Geriatria (SIGG)

\section{(c) (1) () $(9)$}

\section{OPEN ACCESS}

This is an open access article distributed in accordance with the CC-BY-NC-ND (Creative Commons Attribution-NonCommercial-NoDerivatives 4.0 International) license. The article can be used by giving appropriate credit and mentioning the license, but only for non-commercial purposes and only in the original version. For further information: https://creativecommons.org/licenses/by-nc-nd/4.0/deed.en
- administer the SARC-F scale (Strength, Assistance, Rise, Climb, Falls) to evaluate the risk of sarcopenia. If the patient screens positive, clinical tests to evaluate muscle strength (e.g., handgrip strength) should be used to identify treatment needs. If possible, body composition and muscle mass should be tested using bioelectrical impedance analysis (BIA) or dual energy $\mathrm{X}$-ray absorptiometry (DEXA). If there is confirmation of sarcopenia, severity (from moderate to severe) and progression should be evaluated;

- review and monitor nutritional status over time with the aim to modify possible risk factors for malnutrition as soon as possible. In the event of malnutrition (or high risk of malnutrition) a personalized diet plan should be developed. Amino acid supplementation should be considered to improve functioning. In obese patients, personalized diet plans should be developed that aim to achieve appropriate weight loss while maintaining lean body mass, with regular monitoring of weight and comorbidities associated with obesity (e.g., cardiovascular diseases, hypertension, obstructive sleep apnea syndrome). The Mediterranean diet is one of the best nutritional alternatives for most geriatric DM patients. Calcium and vitamin D supplementation is recommended for patients undergoing caloric restriction, to prevent loss of bone mineral density, while physical activity, rather than an increase in protein intake, is important for preserving muscle mass;

- provide recommendations on physical activity adapted to the patient's comorbidities and physical capabilities. 


\section{STRENGTH OF THE RECOMMENDATIONS}

The quality of the evidence is moderate. Recommendations are supported by published evidence.

\section{SUPPORTING EVIDENCE}

See appendix.

\section{AREAS OF UNCERTAINTY AND FUTURE PERSPECTIVES}

DM patients of all ages are recommended to do $30 \mathrm{~min}-$ utes/day of resistance training at an individualized level according to tolerance and personal safety. Nutritional interventions in geriatric DM patients must take into account that inappropriate caloric restriction is sometimes associated with protein restriction, leading to a loss in lean mass. Changing protein intake is, therefore, essential for maintaining and increasing muscle mass. Protein intake of $1.0-1.2 \mathrm{~g} / \mathrm{kg} / \mathrm{protein}$ is recommended, which must be adapted according to the patient's comorbidities and, if necessary (e.g., during an acute event) increased up to $1.5 \mathrm{~g} / \mathrm{kg} /$ day.

The role of dietary interventions in geriatric DM patients deserves further exploration. Several studies have shown that timing and quality of protein intake are important, also depending on the type of physical activity carried out, and that amino acid supplementation may improve muscle performance. Leucine is the amino acid that has been shown to have the best anabolic action, which triggers the Rapamycin pathway. Dietary supplementation with creatine in combination with physical exercise can lead to an increase in muscle mass, strength, and resistance compared to physical exercise alone.

\section{APPENDIX}

DM is an important risk factor for the development of physical disability in older patients ${ }^{1}$.

Sarcopenia is defined as age-related loss in muscle mass and function. Sarcopenia is a complex syndrome, characterized by loss of muscle mass, in isolation or associated with an increase in fat mass. Causes are multi-factorial and include chronic degenerative diseases, age-related changes to the endocrinological system, chronic inflammation, insulin resistance, lack of mobility, and nutritional deficiencies ${ }^{2}$. According to the European Working Group on Sarcopenia in Older People 2 (EWGSOP2) the first parameter that should be assessed during sarcopenia diagnosis is muscle strength, defined as low muscle quality and quantity ${ }^{3}$. A wide variety of clinical and instrumental tests are available for assessing sarcopenia ${ }^{4}$ but the recommended assessment scale is SARC-F, which consists of five questions used to stratify the risk of sarcopenia in older persons ${ }^{5}$, and is a valid tool for assessing patients with T2DM ${ }^{6,7}$.

Sarcopenia is one of the main factors for developing the frailty phenotype proposed by Fried et al. ${ }^{8}$. An individual who develops at least three out of the five clinical components proposed by Fried (weight loss, weakness, exhaustion, slowness, low physical activity level) is defined as frail ${ }^{8}$. Sarcopenia occurs as an intermediate stage during the development of frailty. The prevention and early detection of sarcopenia is a key aspect of the clinical management of geriatric DM patients ${ }^{9}$.

EWGSOP2 has developed several methods for the early identification of sarcopenia. In clinical practice, the most validated, reliable and cost-effective technique for identifying patients at risk of sarcopenia is the Gait Speed Measurement ${ }^{10}$; with a cut-off speed of $<0.8 \mathrm{~m} / \mathrm{s}$ used to define risk of developing sarcopenia. Once a patient has been identified as at-risk, they should be referred for a diagnostic evaluation of muscle mass with Dual Energy-X-ray absorption (DEXA) estimating the appendicular skeletal muscle mass (ASM) index (ASM/height2) and using a cut-off of $7.26 \mathrm{~kg} / \mathrm{m}^{2}$ in men and $5.5 \mathrm{~kg} / \mathrm{m}^{2}$ in women. A valid alternative is the estimation of ASMI using Bioelectrical Impedance Analysis (BIA), with a cut-off of $8.5 \mathrm{~kg} / \mathrm{m}^{2}$ in men over 65 and $5.75 \mathrm{~kg} / \mathrm{m}^{2}$ in women over $65^{11}$.

Muscle mass measurement should then be completed by assessing muscle strength. Handgrip strength correlates with both lower limb muscle capacity and Activities of Daily Living ${ }^{12}$ and, thus, is a useful clinical marker that can be used to screen for sarcopenia in geriatric patients, defined as Handgrip Score $<30 \mathrm{~kg}$ in men and $<20 \mathrm{~kg}$ in women ${ }^{12}$. In the future, handgrip monitoring could be used to assess the effectiveness of therapeutic interventions aimed at slowing down sarcopenia.

The Short Physical Performance Battery (SPPB) is a composite scale used to measure physical performance which can be used to detect sarcopenic early in geriatric persons ${ }^{13}$. It assesses balance, gait, and endurance by assessing the patient's ability to perform various maneuvers, including standing with feet together, walking in tandem, and standing up from a seated position on a chair five times. This last exercise, the Chair Stand Test, can be a reliable index on its own. Scores range from 0 to 12 , with less than 6 indicating poor performance. Frailty is associated with an increased incidence of adverse events such as disability, hospitalization, 
increased risk of falls, and all-cause mortality ${ }^{14}$. As sarcopenia is an intermediate stage that occurs during frailty development, the two syndromes overlap. Thus, it is useful for identifying frail patients as early as possible through rapid screening tests such as the 'FRAIL' Questionnaire Screening Tool, which defines frailty as the presence of $>3$ frailty symptoms or, alternatively, the Cardiovascular Health Study Frailty Screening Scale (CSF) ${ }^{15}$.

It is noteworthy that there are many risk factors for sarcopenia in older diabetic patients and they often have a synergistic effect, suggesting a cause-effect relationship between sarcopenia and $\mathrm{DM}^{16}$ :

- Increasing levels of inflammatory cytokines such as TNF-a and IL-6 have a detrimental effect on muscle mass and function ${ }^{17}$. There is a high correlation between IL-6 serum levels of and muscle mass ${ }^{17}$. In addition, a decline in IGF-1 levels has an antiproteolytic effect ${ }^{18}$.

- Insulin-resistance, on the other hand, causes muscle atrophy by inhibiting the Rapamycin pathway, which is implicated in muscle protein synthesis ${ }^{19}$. Reducing testosterone levels in DM patients reduces muscle protein synthesis ${ }^{20}$.

- DM increases Angiotensin II levels ${ }^{21}$, which are responsible for the cleavage of actin from myosin, which leads to muscular atrophy through proteolysis via the ubiquitin/proteasome pathway. The use of ACE-inhibitors has been associated with an increase in muscle strength ${ }^{22}$.

- Muscle atrophy also increases in the presence of diabetic neuropathy: the degradation of the neuromuscular junction is a predisposing factor for muscle atrophy and loss of muscle strength ${ }^{23}$.

Obesity in DM patients also compounds the situation, due to an often-misunderstood syndrome of sarcopenic obesity, which is characterized by a reduction in lean muscle mass without a decrease in excess adipose tissue mass ${ }^{24}$. The incidence and prevalence of sarcopenic obesity increases with age and is associated with a higher mortality risk in older patients ${ }^{24,25}$. However, sarcopenia linked to malnutrition, which often results from poor protein-caloric intake, inability to eat, and any chronic disease that affects proper nutrition, should not be underestimated in geriatric patients ${ }^{3}$.

Changes to the mouth, which occur in geriatric patients and are often more pronounced in DM patients, such as edentulism, parodontitis, xerostomia, and dysgeusia, can play a central role in the progressive decrease in protein-caloric intake due to worsening chewing and swallowing. This leads to patients choosing to eat mostly soft or creamy foods that are often inadequate for sufficient protein intake unless they are carefully balanced $^{26,27}$. Together with these mouth changes, studies also reveal that cognitive decline plays a role, leading to problems in swallowing, dysphagia, and food choice, which can worsen malnutrition, leading to sarcopenia ${ }^{26-}$ 28. Therefore, a nutrition assessment is recommended during the evaluation and management of geriatric DM patients, which can be carried out with various screening tests (Malnutrition Universal Screening Tool -MUST; Mini Nutritional Assessment-MNA; Malnutrition Screening Tool -MST) that can identify patients at high risk of malnutrition ${ }^{29,30}$.

Numerous drugs are currently available for the treatment of T2DM, but treatment of geriatric DM patients must take into account the risk of sarcopenia associated with this disease. Insulin therapy plays a role in preventing skeletal muscle atrophy by increasing protein synthesis and decreasing degradation, although its protective role has not yet been fully established in geriatrics patients ${ }^{16,31-33}$. Insulin sensitizers have been shown to reduce lean body mass loss by slowing down the process of sarcopenia in geriatric patients. SGLT-2 inhibitors, which have an indirect action on insulin sensitivity, could have a positive effect on sarcopenic patients, even though this has not yet been confirmed in clinical trials ${ }^{31-34}$. The role of metformin is still controversial: numerous studies suggest a catabolic effect through skeletal muscle autophagy ${ }^{31,34}$ while recent cancer models demonstrate a protective role of this drug in the process of muscle mass loss ${ }^{34,35}$.

Due to their mechanism of action, it was initially thought that glitazones could be promising agents for preventing sarcopenia, but their clinical use and efficacy are controversial because they have an unfavorable riskbenefit profile (e.g., increased adverse cardiovascular events) ${ }^{36}$. Some sulfonylureas can cause muscle atrophy associated with loss of muscle protein by reducing fiber size ${ }^{34}$.

Non-pharmacological interventions such as physical activity and personalized diet plans should also be considered for managing DM patients, to improve glucose metabolic compensation and insulin sensitivity ${ }^{37}$. These strategies can have a significant impact on improving body composition by reducing weight and increasing lean mass. Resistance training is the most effective strategy for increasing the muscle mass and function in persons with sarcopenia and for improving the metabolic health of T2DM diabetes. The effect of resistance training on sarcopenia in geriatric DM diabetes patients has not be adequately studied and in clinical practice this intervention may be hindered by chronic diseases that limit mobility ${ }^{38}$.

DM patients of all ages are recommended to do $30 \mathrm{~min}-$ utes/day of resistance training at an individualized

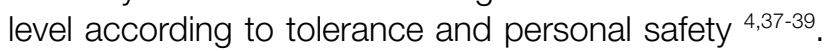
Nutritional interventions in geriatric DM patients must 
take into account that inappropriate caloric restriction is sometimes associated with protein restriction, leading to a loss in lean mass. Changing protein intake is, therefore, essential for maintaining and increasing muscle mass. Protein intake of $1.0-1.2 \mathrm{~g} / \mathrm{kg} /$ day is recommended, which must be adapted according to the patient's comorbidities and, if necessary, increased up to $1.5 \mathrm{~g} / \mathrm{kg} /$ day, for example in case of an acute event ${ }^{39-41}$. Recent studies in geriatric patients without diabetic nephropathy have shown that a daily protein intake of $30 \%$ of total caloric intake can improve glucose metabolism and, them the need of antidiabetic drugs.

The role of dietary interventions in geriatric DM patients is still unexplored ${ }^{39}$. Several studies have shown that timing and quality of protein intake are important, depending on the type of physical activity carried out, and possible amino acid supplementation that could improve muscle performance. The amino acid that has the best anabolic action is Leucine, which triggers the Rapamycin pathway ${ }^{42}$. A randomized trial in a population of sarcopenic geriatric patients demonstrated that a daily intake of at least $8 \mathrm{~g}$ of essential amino acids, including Leucine, led to an increase in muscle mass and insulin-sensitivity with a reduction in TNF-a levels ${ }^{43}$. A randomized, double-blind trial in a population of men over 70 years old, demonstrated that dietary supplementation with Creatine, in combination with physical exercise, led to an increase in muscle mass, strength, and resistance compared to physical exercise alone ${ }^{44}$.

Ethical consideration

None.

\section{Acknowledgement}

The Author would like to deeply thank Dr. Michela D'Avino for her precious collaboration in the drafting and revision of this paper.

\section{Funding}

None.

\section{Conflict of interest}

The Author declares no conflict of interest.

\section{References}

1 Wong E, Backholer K, Gearon E et al. Diabetes and risk of physical disability in adults: a systematic review and metaanalysis. Lancet Diabetes Endocrinol 2013;1:106-114. https://doi.org/10.1016/s2213-8587(13)70046-9

2 Dhillon RJS, Hasni S. Pathogenesis and Management of Sarcopenia. Clin Geriatr Med 2017;33:17-26. https://doi. org/10.1016/j.cger.2016.08.002
3 Cruz-Jentoft AJ, Bahat G, Bauer J, et al. Sarcopenia: revised European consensus on definition and diagnosis. Age Ageing 2019;48:16-31. https://doi.org/10.1093/ ageing/afy169

4 Mijnarends DM, Meijers JM, Halfens RJ, et al. Validity and reliability of tools to measure muscle mass, strength, and physical performance in community-dwelling older people: a systematic review. J Am Med Dir Assoc 2013;14:170178. https://doi.org/10.1016/j.jamda.2012.10.009

5 Malmstrom TK, Miller DK, Simonsick EM, et al. SARC-F: a symptom score to predict persons with sarcopenia at risk for poor functional outcomes. J Cachexia Sarcopenia Muscle 2016;7(1):28-36. https://doi.org/10.1002/jcsm.12048

6 Liccini A, Malmstrom TK. Frailty and sarcopenia as predictors of adverse health outcomes in persons with diabetes mellitus. J Am Med Dir Assoc 2016;17:846-851. https:// doi.org/10.1016/j.jamda.2016.07.007

7 Bouillon K, Kivimaki M, Hamer M, et al. Diabetes risk factors, diabetes risk algorithms, and the prediction of future frailty: the Whitehall II prospective cohort study. J Am Med Dir Assoc 2013;14:851.e1-6. https://doi.org/10.1016/j. jamda.2013.08.016

8 Fried, LP, Walston J. Frailty and failure to thrive. In: Hazzard W, Blass JP, Halter JB, et al. Eds. Principles of geriatric medicine and gerontology. $5^{\text {th }}$ Ed. New York, NY: McGrawHill 2003, pp. 1487-1502.

9 Morley JE, Malmstrom TK, Rodriguez-Manas L, et al. Frailty, sarcopenia and diabetes. J Am Med Dir Assoc 2014;15:853-859. https://doi.org/10.1016/j. jamda.2014.10.001

10 Cruz-Jentoft AJ, Baeyens JP, Bauer JM, et al. Sarcopenia: European consensus on definition and diagnosis: report of the European Working Group on Sarcopenia in Older People. Age Ageing 2010;39:412-423. https://doi. org/10.1093/ageing/afq034

11 Janssen I, Heymsfield SB, Ross R. Low relative skeletal muscle mass (sarcopenia) in older persons is associated with functional impairment and physical disability. J Am Geriatr Soc 2002;50:889-896. https://doi. org/10.1046/j.1532-5415.2002.50216.x

12 Lauretani F, Russo C, Bandinelli S, et al. Age-associated changes in skeletal muscles and their effect on mobility: an operational diagnosis of sarcopenia. J Appl Physiol 2003;95:1851-1860. https://doi.org/10.1152/ japplphysiol.00246.2003

13 PereraS, Mody SH, Woodman RC, et al. Meaningful change and responsiveness in common physical performance measures in older adults. J Am Geriatr Soc 2006;54:743749. https://doi.org/10.1111/j.1532-5415.2006.00701.x

14 Gill TM, Gabhauer EA, Allore HG, et al. Transitions between frailty states among community-living older persons. Arch Intern Med 2006;166:418-423. https://doi.org/10.1001/ archinte.166.4.418

15 Morley JE, Vellas B, van Kan GA, et al. Frailty consensus: a call to action. J Am Med Dir Assoc 2013;14:392-397. https://doi.org/10.1016/j.jamda.2013.03.022 
16 Mesinovic J, Zengin A, De Courten B, et al. Sarcopenia and type 2 diabetes mellitus: a bidirectional relationship. Diabetes Metab Syndr Obes 2019;12:1057-1072. https:// doi.org/10.2147/dmso.s186600

17 Visser M, Pahor M, Taaffe DR, et al. Relationship of interleukin-6 and tumor necrosis factor-alpha with muscle mass and muscle strength in elderly men and women: the Health ABC Study. J Gerontol A Biol Sci Med Sci 2002;57:M32632. https://doi.org/10.1093/gerona/57.5.m326

18 Dehoux M, van Beneden R, Pasko N, et al. Role of the insulin-like growth factor I decline in the induction of atrogin-1/MAFbx during fasting and diabetes. Endocrinology 2004;145:4806-4812. https://doi.org/10.1210/ en.2004-0406

19 Lawrence JC Jr. mTOR-dependent control of skeletal muscle protein synthesis. Int J Sport Nutr Exerc Metab 2001;11(Suppl):S177-185. https://doi.org/10.1123/ijsnem.11.s1.s177

20 Sinha-Hikim I, Cornford M, Gaytan H, et al. Effects of testosterone supplementation on skeletal muscle fiber hypertrophy and satellite cells in community-dwelling older men. J Clin Endocrinol Metab 2006;91:3024-3033. https://doi. org/10.1210/jc.2006-0357

21 Nicola W, Sidhom G, El Khyat Z, et al. Plasma angiotensin $\|$, renin activity and serum angiotensin-converting enzyme activity in non-insulin dependent diabetes mellitus patients with diabetic nephropathy. Endocr J 2001;48:25-31. https://doi.org/10.1507/endocrj.48.25

22 Carter CS, Onder G, Kritchevsky SB, et al. Angiotensinconverting enzyme inhibition intervention in elderly persons: effects on body composition and physical performance. J Gerontol A Biol Sci Med Sci 2005;60:1437-1446. https:// doi.org/10.1093/gerona/60.11.1437

23 Casellini CM, Vinik Al. Clinical manifestation and current treatment options for diabetic neuropathies. Endocr Pract 2007;13:550-566. https://doi.org/10.4158/ep.13.5.550

24 Kalinkovich A, Livshits G. Sarcopenic obesity or obese sarcopenia: a cross talk between age-associated adipose tissue and skeletal muscle inflammation as a main mechanism of the pathogenesis. Ageing Res Rev 2017;35:200221. https://doi.org/10.1016/j.arr.2016.09.008

25 Johnson Stoklossa CA, Sharma AM, Forhan M, et al. Prevalence of sarcopenic obesity in adults with Class II/III obesity using different diagnostic criteria. J Nutr Metab 2017;2017:7307618. https://doi. org/10.1155/2017/7307618

26 Azzolino D, Passarelli PC, De Angelis P, et al. Poor oral health as a determinant of malnutrition and sarcopenia. Nutrients 2019;11:2898. https://doi.org/10.3390/ nu11122898

27 Bakker MH, Vissink A, Spoorenberg SLW, et al. Are edentulousness, oral health problems and poor health-related quality of life associated with malnutrition in communitydwelling elderly (aged 75 years and over)? A cross-sectional study. Nutrients 2018;10:1965. https://doi.org/10.3390/ nu10121965
28 Kossioni AE. The association of poor oral health parameters with malnutrition in older adults: a review considering the potential implications for cognitive impairment. Nutrients 2018;10:1709. https://doi.org/10.3390/nu10111709

29 Donini LM, Poggiogalle E, Molfino A, et al. Mini-nutritional assessment, malnutrition universal screening tool, and nutrition risk screening tool for the nutritional evaluation of older nursing home residents. J Am Med Dir Assoc 2016;17:959.e11-8. https://doi.org/10.1016/j. jamda.2016.06.028

30 Saintrain MVL, Sandrin RLESP, Bezerra CB, et al. Nutritional assessment of older adults with diabetes mellitus. Diabetes Res Clin Pract 2019;155:107819. https://doi. org/10.1016/j.diabres.2019.107819

31 Fanzani A, Conraads VM, Penna F, et al. Molecular and cellular mechanisms of skeletal muscle atrophy: an update. J Cachexia Sarcopenia Muscle 2012;3:163-179. https://doi. org/10.1007/s13539-012-0074-6

32 Lee CG, Boyko EJ, Barret-Connor E, et al. Insulin sensitizers may attenuate lean mass loss in older men with diabetes. Diabetes Care 2011;34:2381-2386. https://doi. org/10.2337/dc11-1032

33 Cetrone M, Mele A, Tricarico D. Effects of the antidiabetic drugs on the age-related atrophy and sarcopenia associated with diabetes type II. Curr Diabetes Rev 2014;10:231 237. https://doi.org/10.2174/1573399810666140918121 022

34 Kalaitzoglou E, Fowlkes JL, Popescu I, et al. Diabetes pharmacotherapy and effects on the musculoskeletal system. Diabetes Metab Res Rev 2019;35:e3100. https//doi. org/10.1002/dmrr.3100

35 Oliveira AG, Gomes-Marcondes MC. Metformin treatment modulates the tumour-induced wasting effects in muscle protein metabolism minimising the cachexia in tumourbearing rats. BMC Cancer 2016;16:418. https://doi. org/10.1186/s12885-016-2424-9

36 Starner $\mathrm{Cl}$, Schafer JA, Heaton AH, et al. Rosiglitazone and pioglitazone utilization from January 2007 through May 2008 associated with five risk-warning events. J Manag Care Pharm 2008;14:523-531. https://doi.org/10.18553/ jmcp.2008.14.6.523

37 Vlietstra L, Hendrickx W, Waters DL. Exercise interventions in healthy older adults with sarcopenia: a systematic review and meta-analysis. Australas J Ageing 2018;37:169-183. https://doi.org/10.1111/ajag.12521

38 Hovanec N, Sawant A, Overend TJ, et al. Resistance training and older adults with type 2 diabetes mellitus: strength of the evidence. J Aging Res 012;2012:284635. https:// doi.org/10.1155/2012/284635

39 Larsen RN, Mann NJ, Maclean E, et al. The effect of high-protein, low-carbohydrate diets in the treatment of type 2 diabetes: a 12 month randomised controlled trial. Diabetologia 2011;54:731-740. https://doi.org/10.1007/ s00125-010-2027-y 
40 World Health Organization. Protein and amino acid requirements in human nutrition: report of a joint FAO/WHO/UNU expert consultation. Geneva, WHO Press, 2007. WHO Technical Report Series no. 935.

41 Bauer J, Biolo G, Cederholm T, et al. Evidence-based recommendations for optimal dietary protein intake in older people: a position paper from the PROT-AGE Study Group. J Am Med Dir Assoc 2013;14:542-559. https://doi. org/10.1016/j.jamda.2013.05.021

42 Drummond MJ, Rasmussen BB. Leucine-enriched nutrients and the regulation of mammalian target of rapamycin signaling and human skeletal muscle protein synthesis. Curr Opin Clin Nutr Metab Care 2008;11:222-226. https:// doi.org/10.1097/mco.0b013e3282fa17fb
43 Solerte SB, Gazzaruso C, Bonacasa R, et al. Nutritional supplements with oral amino acid mixtures increases whole-body lean mass and insulin sensitivity in elderly subjects with sarcopenia. Am J Cardiol 2008;101:69E-77E. https://doi.org/10.1016/j.amjcard.2008.03.004

${ }_{44}$ Chrusch MJ, Chilibeck PD, Chad KE, et al. Creatine supplementation combined with resistance training in older men. Med Sci Sports Exerc 2001;33:2111-2117. https:// doi.org/10.1097/00005768-200112000-00021

\author{
This statement is: \\ 囚 Recommendation (supported by published evidence) \\ $\square$ Best practice (supported by expert opinion)
}

Quality of the evidence (in the case of recommendation):
$\square$ Low
$\bigotimes$ Moderate
$\square$ High

